
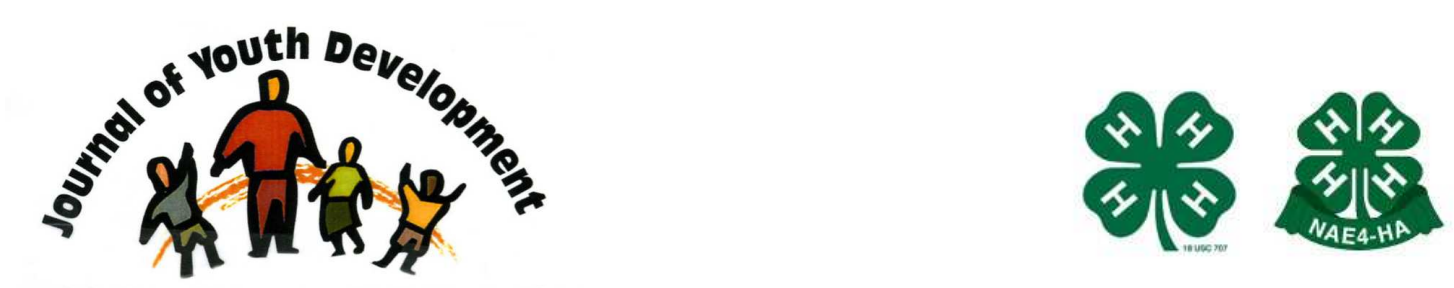

Bridging Research \& Practice

\title{
The Leadership Program's Violence Prevention Project: Infusing the Arts into Conflict Resolution
}

Lisa M. Chauveron

The Leadership Program

New York, NY

lisa@theleadershipprogram.com 


\title{
JOURNAL OF YOUTH DEVELOPMENT \\ bridging research and practice

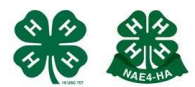

Volume 7, Number 2, Summer 2012

Article 120702RR002

\section{The Leadership Program's Violence Prevention Project: Infusing the Arts into Conflict Resolution}

Lisa M. Chauveron

The Leadership Program

\begin{abstract}
While the demand for youth violence prevention programs increases, the ability of the traditional school day schedule to accommodate violence prevention program time requirements has diminished. School reforms, such as No Child Left Behind, have pressed schools to focus more tightly on academics, often to the exclusion of subjects such as physical education and the arts. Viable violence prevention programs must offer components that supplement classroom curriculum as well as reduce violence and strike a balance between brevity and effectiveness. The Leadership Program's (TLP) universal Violence Prevention Project (VPP) meets this call with a conflict resolution model for students in urban schools.

The curriculum is based on a conceptual framework derived from prevention science and positive youth development delivered through the vehicle of the arts. Utilizing an engaging hybrid prevention program, this high quality 12 session model melds fidelity and adaptation to yield effective evaluation outcomes.
\end{abstract}

\section{Introduction}

The continuing intractability of youth violence commands maintained interest in universal, school-based violence prevention programs from researchers, policy-makers, and school administrators alike. Conversely, while the demand for youth violence prevention programs increases, the ability of the traditional school day schedule to accommodate prevention program time requirements has diminished. School reforms, such as No Child Left Behind, have pressed schools to focus more tightly on academics, often to the exclusion of less academic subjects like physical education, music, or art. Resultantly, classroom time for non-academic instruction is scarce. As underserved urban schools with the highest need for youth violence prevention also have the greatest demand for academic improvement, viable programs must offer components that supplement classroom curriculum, reduce violence and strike a balance between brevity and effectiveness. 


\section{Program Design}

One such program, The Leadership Program's (TLP) universal Violence Prevention Project (VPP), offers a conflict resolution model for students in urban schools based on a conceptual framework derived from prevention science and positive youth development. The program is delivered through the vehicle of the arts. Schools are provided with highly trained classroombased Leadership facilitators that implement a violence prevention program. Contents include:

- two individualized planning sessions with teachers and school principals prior to implementation,

- 12 interactive lessons for students, and

- two evaluation sessions, cumulatively comprising a "unit."

The curriculum allows schools to address youth violence and offer students more opportunities to experience the arts.

VPP was designed to deliver evidence-based violence prevention information in an engaging format with specific attention to the context of urban schools and students. More specifically, VPP aims to promote and develop competence, reinforcing participating youth's ability to adapt and overcome challenges common in many urban schools. Such resilience manifests itself in the context of significant challenges to development (Masten \& Coatsworth, 1998). Defined by The National Research Council (1996) as "patterns that protect children from adopting problem behaviors in the face of risk," resilience is also described as an "inborn capacity for self-righting" that appears to "transcend ethnic social class, geographical and historical boundaries" (Werner \& Smith, 1992), suggesting a nature-driven protective mechanism for human development (Matsen, 1994). Effective interventions in violence prevention reinforce natural social bonds that give meaning to one's life and a reason for commitment and caring (Werner \& Smith, 1989).

Similarly, VPP is focused on the development of participants' resilience, and builds on constructs of positive youth development encouraging forging meaningful interpersonal bonds between youth and a caring adult (Perkins \& Caldwell, 2005). A key element of this process is the recognition of universal, shared needs for community, continuity, and connection to others (Sergiovanni \& Starratt, 1993). This is articulated by Pittman (1991) as roles, responsibilities, relationships, resources, relevance, reality, respect, and recognition, instrumental in establishing students' perception that they are important members of their school and community. In this way, program participants not only learn to protect themselves from negative behaviors, but also develop positive, pro-social, and non-violent behavior.

Many VPP schools are in underserved communities that represent threatening and difficult environments for youth. Given the presence of gangs, availability of drugs and firearms, and exposure to violence and racial prejudice, youth throughout urban centers are at risk for developmental problems (Dryfoos, 1990; Gorman-Smith, et al, 1998; alpha order). Existing research has shown VPP's success with New York City students on in-house evaluation reports (e.g., Patterson, 2005), placing VPP under review for SAMHSA's National Registry of EvidenceBased Programs and Practices.

Utilizing what Castro-Gonzalez and colleagues (2004) dub a "hybrid prevention program," VPP's curriculum accounts for differences in class functioning, socio-cultural relevancy, special needs, school-specific issues, and other factors essential to local and large scale implementation 
success (Castro-Gonzalez, Barrera, \& Martinez, 2004; Elliott \& Mihalic, 2004; Kumpfer, Alvarado, Smith \& Bellamy, 2002). VPP facilitators teach age-appropriate core components and principles that lead to violence prevention: positive self-concept, leadership, decision-making, group dynamics, vision and imagination, and conflict resolution.

To complement the six core components, trainers select six additional topics from a bank of choices such as social responsibility, empathy, positive thinking, community-building, and character development. A syllabus with the six core lessons and six supplemental lessons is decided upon jointly by the classroom teacher and VPP facilitation team. Supplemental lesson selection from the bank is based on an assessment of student, teacher, and principal needs tailored individually for every school. No sessions are dropped as a result of adaptation; rather, exercises are modified to take advantage of teachable moments to integrate class input and group dynamics into lesson plans. To track curriculum and syllabus progress, facilitators turn in weekly Lesson Logs.

Each of VPP's 12 classroom-based lessons, which occur during a normal school day period (about 45 minutes), is formatted in the same manner. The curriculum draws largely from the experiential learning cycle, a structured learning sequence that guides multiple styles of learners through experience-based activities (Pfeiffer \& Jones, 1975, 1983). With this methodology, facilitators create continuous threads from one experience to the next, letting learners process an activity through 5 stages of comprehension culminating with concept or skill application.

The experiential learning cycle is applied throughout the 4 segments of each lesson: the aim, warm-up, main activity, and closing. Facilitators start by posting an aim in the classroom, a question-phrased theme connecting the day's activities. Any lesson vocabulary terms are defined and explained to the class. The warm-up then occurs, consisting of an ice-breaker or similar team-building activity for the whole group, always involving some form of physical movement. Next, in the main activity, the entire class or small groups participate in role plays, trust games, cooperative work, or discussion, or individual work such as drawing or worksheet completion.

Finally, at the closing, the facilitator asks processing questions reflecting on the day's activities, ultimately answering the question posed by the aim. At the end of each unit, students complete a final project that integrates their newly acquired skills, building community as they collaboratively create an original visual or performance artwork communicating applied VPP principles in a manner meaningful to them.

Given the potential impacts of school principal support on programmatic outcomes (Kam, Greenberg, \& Walls, 2003) VPP implementation includes collaboration with principals before classroom-based lessons begin and continues throughout the unit. Once initial principal support is garnered, teacher planning sessions ensue, in which teams jointly identify issues specific to individual classes further honing objectives and aims most appropriate for participants. Facilitators include this input when determining which non-core lessons to teach, and model VPP techniques for teacher use. This collaborative process allows contextually relevant issues to be addressed, creates teacher and principal buy-in, and encourages sustainability of VPP principles after program completion.

Serving at-risk, low-income students in urban schools requires cultural appropriateness in terms of both curricular framework and trainer demographics. Such factors have been shown to be 
imperative to intervention success (Kumpfer, Alvarado, Smith \& Bellamy, 2002). Field tested in NYC classrooms for more than 12 years, VPP's information delivery content and style is built to resonate with racially/ethnically, culturally, religiously, and ability diverse students. Facilitators undergo training sessions addressing the diversity of students in VPP units. Moreover, VPP $s$ staff make-up mirrors the student diversity common in urban schools, helping them achieve buy-in from students.

\section{Staffing Model}

A key component of programmatic success is the high quality of VPP staff screening and training. To join this cadre of part-time facilitators, applicants must have a Bachelor's degree, at least 2 years of experience working with urban youth, and visual/performing arts backgrounds, skills they must utilize to create projects with students. After passing a multi-stage process, about $25 \%$ of those who apply are selected for employment.

Once selected, all facilitators complete mandatory 20-hour training. With intensive focus on classroom management strategies (including building community, methods for engaging students, and TLP's style of behavior management), and the experiential learning cycle, facilitators are introduced to core curricular lessons and the lesson bank. Using role play exercises, they learn to address teacher and staff buy-in issues as well as implementation obstacles and strategies to best overcome them. Facilitators are taught to withstand the instability of urban public schools and effectively build and maintain relationships with classroom teachers.

Upon completion, they are assigned to a unit for program implementation, and schedule time with their newly assigned Lead Trainer to begin teacher and principal meeting set-ups. The Lead Trainer is a VPP facilitator with at least three years of experience implementing the program successfully, certified by VPP staff as a gold standard facilitator. Serving as a mentor for other facilitators, Lead Trainers provide individual support through every stage of project implementation.

Supplementary trainings are offered throughout the year, providing in-depth focus on related topics. Facilitators must also attend monthly staff meetings to discuss unit progress, share challenges and create solutions. To ensure quality implementation, all facilitators are observed in-class by a program observer at least once per school year; newer facilitators are observed twice. Results direct action steps for improvement and coaching plans. Thus, staff is supported and quality is maintained throughout the duration of each unit.

\section{Replication}

Resources to fund VPP implementation can be found in school-based, local and state educational funds. For more information, please visit www.theleadershipprogram.com. 


\section{References}

Castro-Gonzalez, F., Barrera, M., \& Martinez, C.R. (2004). The Cultural Adaptation of Prevention Interventions: Resolving Tensions between Fidelity and Fit. Prevention Science, 5(1), 41-45.

Dryfoos, J.G. (1990). Adolescents at risk: Prevalence and prevention. New York Oxford University Press.

Elliott, D.S., \& Mihalic, S. (2004). Issues in Disseminating and Replicating Effective Prevention Programs. Prevention Science, 5(1), 47-53.

Gorman-Smith, D., Tolan, P.H., Loeber, R., \& Henry, D.B. (1998). Relation of family problems to patterns of delinquent involvement among urban youth. Journal of Abnormal Child Psychology $26,319-333$.

Kam, C.M., Greenberg, M.T., \& Walls, C.T. (2003). Examining the role of implementation quality in school-based prevention using the PATHS curriculum. Promoting Alternative Thinking Skills Curriculum. Prevention Science, 4(1), 55-63.

Kumpfer, K., Alvarado, R., Smith, P., \& Bellamy, N. (2002). Cultural sensitivity and adaptation in family-based prevention interventions. Prevention Science, 3(3), 241-246.

Matsen, A.S. (1994). Resilience in individual development: Successful adaptation despite risk and adversity. In M.C. Wang \& E.W. Gordon (Eds.), Educational resilience in inner-city America: Challenges and prospects. Hillsdale, N.J.: Erlbaum.

Matsen, A.S., \& Coatsworth, J.D. (1998). The development of competence in favorable and unfavorable environments: Lessons from research on successful children. American Psychologist, 53, 205 -220.

National Research Council, Institute of Medicine. (1996). Youth Development and Neighborhood Influences: Challenges and Opportunities, Summary of a workshop. Report by the Committee on Youth Development, Board on Children, Youth, and Families, Commission on Behavioral and Social Sciences and Education. (Eds.) R. Chalk and D.A. Phillips. Washington, DC: National Academy Press.

Patterson, C.A. (2005). Measuring positive youth development in the context of program model transition. New York University, New York, NY.

Perkins, D.F., \& Caldwell, L. (2005). Resiliency, protective processes, promotion, and community youth development. In Witt, P., \& Caldwell, L. (Eds.), Recreation and youth development (149-167). State College, PA: Venture Publishing.

Pfieffer, J.W., \& Jones, J.E. (1975). Reference guide to handbooks and annuals. La Jolla, CA: University Associates.

Pfieffer, J.W., \& Jones, J.E. (1983). A Handbook of Structured Experiences for Human Relations Training (Vols. 1-5). (Vol. 1 thru 5). La Jolla, California: University Associates. 
Pittman, K.J. (1991). Promoting youth development: Strengthening the role of youth serving and community organizations. . Washington, D.C.: Center for Youth Development and Policy Research.

Sergiovanni, T.J., \& Starratt, R.J. (1993). Supervision: A Redefinition. New York, NY: McGrawHill.

Werner, E., \& Smith, R. (1989). Vulnerable but Invincible: A Longitudinal Study of Resilient Children and Youth. New York Adams, Bannister, and Cox.

Werner, E., \& Smith, R. (1992). Overcoming the odds: High-risk children from birth to adulthood. New York Cornell University Press.

(C) Copyright of Journal of Youth Development Bridging Research and Practice. Content may not be copied or emailed to multiple sites or posted to a listserv without copyright holder's express written permission. However, users may print, download or email articles for individual use. 